\title{
METHOD FOR IDENTIFYING SUITABLE COMPONENTS FOR FUNCTIONAL INTEGRATION - FOCUSING ON GEOMETRIC CHARACTERISTICS
}

\author{
Voigt, Michael P. (1); \\ Klaiber, Dominik (2); \\ Hommel, Patrick (1); \\ Roth, Daniel (1); \\ Binz, Hansgeorg (1); \\ Vietor, Thomas (2) \\ 1: University of Stuttgart; \\ 2: Braunschweig University of Technology
}

\begin{abstract}
The approach of functional integration has the potential to solve challenges regarding lightweight design and resource efficiency since the number of parts and therefore the weight and needed installation space can be reduced. One important step in developing integrative concepts is the preselection of suitable functions or components. Previous methods of pre-selection take various aspects into account. However, pre-selection based on these methods usually requires additional tables and forms, whose preparation and editing quickly becomes time-consuming. At the same time, most of the development engineers are working on CAD models. However, their use in the selection of suitable integration partners is not yet supported sufficiently. The development of more than 80 concepts on five different vehicles has shown that the consideration of geometric properties (position, orientation, size) is effective, as they can be identified with minimal analysis effort while working on CAD. In this paper a four-step procedure is presented how integration partners can be identified directly on the basis of CAD models. A following evaluation with development engineers in practice completes the research.
\end{abstract}

Keywords: Lightweight design, Design methods, Computer Aided Design (CAD), integration of function, geometric characteristics

\author{
Contact: \\ Voigt, Michael P. \\ University of Stuttgart \\ Institute for Engineering Design and Industrial Design \\ Germany \\ michael.voigt@iktd.uni-stuttgart.de
}

Cite this article: Voigt, M. P., Klaiber, D., Hommel, P., Roth, D., Binz, H., Vietor, T. (2021) 'Method for Identifying Suitable Components for Functional Integration - Focusing on Geometric Characteristics', in Proceedings of the International Conference on Engineering Design (ICED21), Gothenburg, Sweden, 16-20 August 2021. DOI:10.1017/ pds.2021.466 


\section{INTRODUCTION AND MOTIVATION}

Increasing product attractiveness requires new functions, which often leads to a higher number of components installed (Bhardwaj et al. 2021). At the same time companies (e.g. in the automotive industry) target low weight and minimal installation space and therefore a reduced number of components to optimize their products and reduce the carbon footprint (Delogu et al., 2016). Here a conflict of objectives occurs. The approach of functional integration reduces this conflict because a certain amount of functions can be fulfilled by less function carriers (Ehrlenspiel et al., 2007). The reduced number of parts which are needed to fulfil the required functionality usually results in a smaller installation space or lower weight (Gumpinger et al., 2009; Ziebart, 2012; Klaiber et al., 2019). In particular, analyses transcending the boundaries of assemblies can help to tap unused potential because products are divided into subsystems during development due to their high complexity and are often worked on independently of each other (Ziebart, 2012). Before realizing functional integrated solutions (Ehrlenspiel and Meerkamm, 2017; Moritz et al., 2019; Klaiber et al., 2019), a preselection of the elements to be considered is recommended by the methods presented in the following section.

Current methods for the preselection of functions for functionally integrated concepts consider various aspects (all aspects found are described in Section 2), such as the selection of materials (Gumpinger et al., 2009), the extent to which the function is fulfilled integrally (Köckerling and Gausmeier, 2003) or the level of production costs in relation to the functionality of the component (Wulf and Schuller, 2000). But these methods (Pimmler and Eppinger, 1994; Köckerling and Gausmeier, 2003; Franke et al., 2005; Ziebart, 2012) mostly use additional forms or tables and when applying they easily get timeconsuming while preparing and editing. Considering the fact that nowadays most developments take place with the help of Computer Aided Design (CAD) models, the question arises whether there is a suitable method that can mainly be carried out directly on CAD-models. Matching this question, Izard and Spelke (2009) describe that geometric properties (e.g., position, orientation, size) can already be intuitively identified at an early age. Taking all the mentioned aspects into consideration while working at functionally integrated concepts, one questions remains unanswered: How can suitable integration partners for integrative concepts be found based on the geometric properties? In the following section, a literature review on pre-selection methods in the context of functional integration with the corresponding research gap is presented.

\section{LITERATURE REVIEW AND RESEARCH GAP}

There are various methods and approaches for selecting suitable functions for functionally integrative concepts in literature. In the following section, a brief summary of a detailed literature analysis is provided.

Wulf and Schuller (2000) describe a procedure in which the integration potential of the functions is identified by comparing the production costs of the assembly with its functionality. A "redesign" of the previous assemblies is justified by their accordingly high production costs.

According to Köckerling and Gausemeier (2003), useful functions with possible partial solutions are compared in a matrix that evaluates how well a partial solution fulfils the useful function. Based on this evaluation, it can be determined whether a partial solution can be used for multiple functions in an integrated manner.

Gumpinger et al. (2009) describe an approach for preselecting functions for integrative concepts based on material requirements. To identify suitable integration partners, possible working principles of the functions to be integrated and their requirements for material selection are compared. Working principles that can be realized with the same materials are suitable for integrative concepts.

Ziebart (2012) presents an approach that considers the change in product states over time in order to select suitable integration partners. In practice, conflicts can appear when searching for integrative concepts as the scope of functions is "timeless". Instead, products often pass through different operating states during use. Various function sets can be assigned to these states that alternate over time. One potential solution for the apparent conflicts is to consider functions as being "switched on" or "switched off" according to their operating states. Ziebart presents a function-state matrix form for identifying the apparently conflicting functions and corresponding switching signals.

According to Wagner et al. (2017), functions for integrative concepts can be selected when examining the extent to which function-relevant properties can be reconciled with production-related properties. 
For this purpose, a technical system is divided into its components, and the function-related and production-related properties are compared for each function. If multiple function-related properties match the production-driven properties, they can be implemented together in an integrative concept. Subsequently, the partial solutions are combined to form the functionally integrated technical system. Franke et al. (2005) describe an initial approach in which the positioning of functions is considered in the selection of suitable integration partners. The collected functions are entered into a form and sorted. Subsequently, an analysis is conducted to determine whether the relevant functions are suitable for integrative concepts. Integration partners are identified by grouping identical or similar functions in spatial proximity to each other. However, the classification to different location-binding types is not taken into account.

Using the Design Structure Matrix (DSM) according to Pimmler and Eppinger (1994), elements of existing products can be analyzed and grouped together based on their interactions with each other. The resulting modules exhibit a high level of interaction between elements, while the interaction between the modules is simultaneously reduced. This procedure can be interpreted as a method for selecting suitable functions for integrative concepts since the modules have high need for functionally integrated concepts (Pimmler and Eppinger, 1994). In practice, product architectures are rarely completely redesigned (Pimmler and Eppinger, 1994). In the context of a change in the position of function carriers, the currently available installation space is therefore always crucial.

According to the literature review, no suitable approach could be found which answers the above question. However, it was recognized that when analyzing existing products with regard to potential for functional integration, there is a high correlation between the geometric properties and the positioning. In literature, Franke et al. (2005) and Pimmler and Eppinger (1994) already consider positioning aspects but neglect the currently available installation space. This represents a research gap, as the research question raised has not yet been answered. This research gap is addressed by the following method.

\section{DEVELOPED METHOD}

In this section, the method for preselecting suitable functions for integrative concepts is presented. The aims are the classification of function carriers with regard to geometric properties in the context of functional integration. For this purpose, more than 80 integrative concepts based on geometric properties were developed using $\mathrm{CAD}$ data of five different vehicles. It has been shown that considering the position binding in relation to the current installation space situation is particularly effective in identifying suitable integration partners.

\subsection{Constraints to application of the method}

The method is especially suitable for the further development of existing products. The existing range of functions can be analyzed, and new functions can be integrated. The benefit of the method increases for complex, multifunctional products. The more function carriers and subassemblies are considered; the more diverse integrative concepts are conceivable by relocating elements across assembly boundaries. Additionally, only technical functions are examined in this paper. The functional integration of aesthetic, economic or social functions (Aurisicchio et al., 2011) may require an adapted approach.

\subsection{Procedure of the method in four steps}

The developed procedure for identifying integration partners is divided into four steps, which are illustrated in Figure 1.

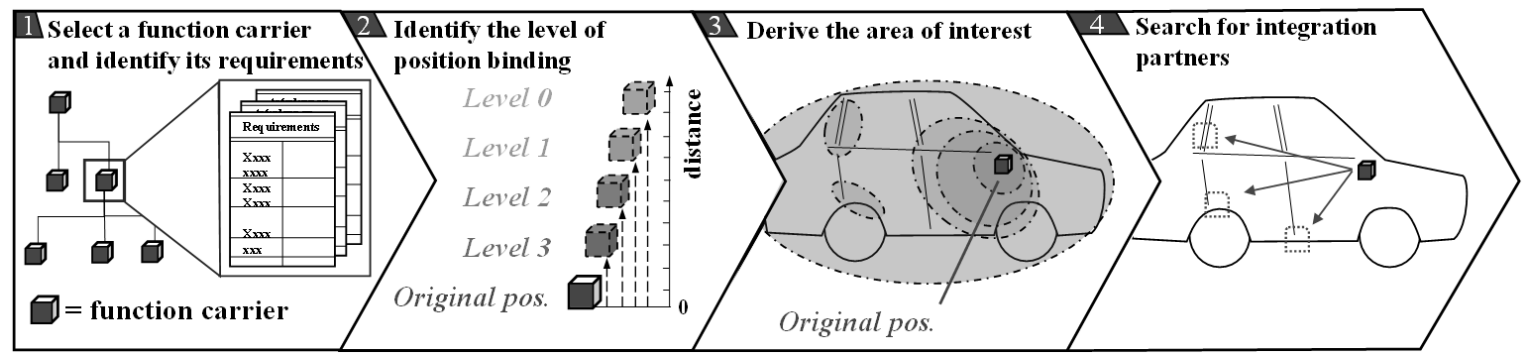

Figure 1. Schematic illustration of the four-step procedure 
Step 1: Select a function carrier and identify its requirements

At the outset, the technical system is analyzed, and the function carrier whose function should be integrated is selected. This selection depends on the designer's objective and therefore varies. Since the strategy of functional integration particularly influences the weight, the installation space, and the required number of parts, the motivation of the analysis might be to identify particularly heavy, large, or multipartite elements. Further motivators for lightweight design are presented for example by Laufer et al. (2019). At the same time, function carriers with particularly interfering positioning or newly added function carriers can be effectively selected.

Subsequently, the requirements of the function carrier need to be identified. For the first step of the method, the requirements regarding positioning are focused. According to Ehrlenspiel and Meerkamm (2017), it is necessary to differentiate between firm requirements and interval requirements. Firm requirements clearly define the position of the function carrier. Interval requirements define limits within which the requirement is fulfilled. It has to be decided individually how important it is to meet the interval requirements close to the maximum valuation. One frequently occurring example is the requirement for minimum use of material, force, and energy transmission lines.

\section{Step 2: Identify the level of position binding}

Depending on the requirements identified in step 1, the function carriers can be assigned to one of four levels of position binding. Table 1 describes the individual levels using different examples. With a decreasing level, the amount of movement allowed by the function carrier increases, and with it the possibility of finding suitable integration partners. However, the level of position binding does not yet provide any information on suitability for integrative concepts.

\section{Table 1. Level of position binding}

\begin{tabular}{|l|l|}
\hline $\begin{array}{l}\text { Level of } \\
\text { position } \\
\text { binding }\end{array}$ & Description and examples \\
\hline Level 3 & $\begin{array}{l}\text { Tied to a specific position } \\
\text { The position of the function fulfilment is set by sufficient firm and/or interval } \\
\text { requirements. } \\
\text { Example: The windshield wiper is linked to the associated windshield. }\end{array}$ \\
\hline Level 2 & $\begin{array}{l}\text { Partially tied to a specific position } \\
\text { The position of the function carrier is mostly set by interval requirements. A change } \\
\text { in the location is allowed within the interval limits. In most cases, the function } \\
\text { carriers interact with each other within an assembly or have special ergonomic } \\
\text { positioning requirements. } \\
\text { Examples: Sensors are tied to their operating range. Displays and control units are } \\
\text { tied to ergonomically determined zones. }\end{array}$ \\
\hline Level 1 & $\begin{array}{l}\text { Mainly position-independent } \\
\text { These are function carriers with either one or two tied ends but a variable course. This } \\
\text { applies to wires, pipes, or ducts. } \\
\text { Example: Air ducts have with the connection to the A/C unit at least one tied end. } \\
\text { However, the course of the air duct is not position-dependent. }\end{array}$ \\
\hline Level 0 & $\begin{array}{l}\text { Position-independent } \\
\text { The function carrier fulfils the required function regardless of its position. These are } \\
\text { mostly storage containers or tanks. } \\
\text { Example: Air tanks or reservoirs for washer fluid can be positioned independently } \\
\text { regarding the function fulfilment of storing a medium. }\end{array}$ \\
\hline
\end{tabular}

Step 3: Derive the area of interest

In the third step, the levels of position binding can be used to derive the area of interest for the package space analysis. The higher the level of the position binding, the smaller the area that can be set. The absolute size of the area is individual for each case and is determined by the firm and interval requirements of the function carrier. The description of the area of interest is given in Table 2. 
Table 2. Description of the area of interest depending on the level of position binding

\begin{tabular}{|l|l|}
\hline $\begin{array}{l}\text { Level of } \\
\text { position } \\
\text { binding }\end{array}$ & Description of the area of interest \\
\hline Level 3 & $\begin{array}{l}\text { Integration can only be realized immediately adjacent to the function carrier. The area } \\
\text { of interest is therefore limited to directly surrounding elements. }\end{array}$ \\
\hline Level 2 & $\begin{array}{l}\text { The area of interest increases in line with the limits of the interval requirements. } \\
\text { Therefore, elements in the wider environment of the function carrier are also } \\
\text { considered. }\end{array}$ \\
\hline Level 1 & $\begin{array}{l}\text { To find installation space for integrative concepts with conducting functions, the } \\
\text { course is varied based on the tied components (defined connections). The } \\
\text { components that touch the possible path when the course is varied form the area of } \\
\text { interest for the further procedure. }\end{array}$ \\
\hline Level 0 & $\begin{array}{l}\text { In the case of position-independent function carriers, the area of interest is the } \\
\text { complete technical system, including parts which are non-intuitive at first sight. }\end{array}$ \\
\hline
\end{tabular}

\section{Step 4: Search for integration partners}

The aim of the analysis is to identify function carriers in the defined area of interest that are suitable for developing integrative concepts, whereby the available installation space is an important indicator. In an initial step, a suitable installation space must be found. Here, it is also possible to combine several small installation spaces. For this purpose, the requirements identified in the first step are considered. Some examples of requirements concerning the installation space are the required size, shape, or position.

At this point, the possibilities of integrative concepts become numerous. A few examples are given:

1. From the perspective of fulfilling the function itself, the integration of pressurized gas tanks does not require a special position or orientation. However, a compact, round installation space is suitable (especially at higher pressures) as the tensions in the tank are homogenized in this case.

2. Liquid storage tanks usually require a minimum level at which the drain of the tank is located to allow complete draining. Accordingly, vertically oriented installation spaces are particularly suitable for the integration of liquid tanks.

3. The integration of media pipes is suitable in long profiles with a consistent cross-section like extruded profiles. Here, the preferred integration orientation is in the profile's longitudinal direction.

4. Further concept possibilities can be found in literature (Klaiber et al., 2019).

After identifying potential integration partners on the basis of the available installation space, further requirements of the complete system must be taken into account. Common examples are:

1. Safety requirements (e.g., Euro NCAP)

2. Regulations and laws (e.g., EU regulations on emissions reduction)

3. Accessibility (e.g., for maintenance and servicing)

4. Position of the center of gravity (e.g., stability or vehicle dynamics)

5. Possibility of disassembling and recycling

6. Lightweight design (e.g., to save resources, emissions, and/or costs)

7. Acoustics (e.g., vehicle comfort)

To facilitate a quick and simple procedure, and to change as few boundary conditions as possible, the existing working principle of the function is initially used. If no suitable integration partners are found within the area of interest, the working principle of the elements can be changed. This results in altered requirements and can open up new possibilities for positioning. In this case, it is recommended to repeat the four steps of the procedure. After identifying suitable integration partners, the developer's existing "idea" of a possible integrative concept has to be substantiated and developed further. For this purpose, the existing methods for developing integrative concepts can be used (Klaiber et al., 2019; Ehrlenspiel and Meerkamm, 2017). 


\section{CASE STUdies}

In this section, the procedure presented above is applied to a Porsche Panamera and also to a building. Due to their wide variety of components, cars and increasingly also (adaptive) buildings are considered to be complex technical systems. To master complexity in the design process, the entire system is broken down into a large number of subsystems. Examples for a car are the body-in-white, the chassis, the electrical system, and the powertrain. These subsystems are further subdivided and are often developed separately from other subsystems (e.g., on the assembly level). Below, three examples are given to show how integration potential can be realized from a holistic perspective.

\subsection{Example 1: Compressed-air tank}

The first case study considers a compressed-air tank (Step 1). The tank is part of the air-suspension system in the vehicle. The air-suspension compressor accumulates compressed air, which is stored in the tank such that it can be released when the car needs to be lifted. Figure 2 shows the position of the compressed-air tank in the body-in-white of a Porsche Panamera.

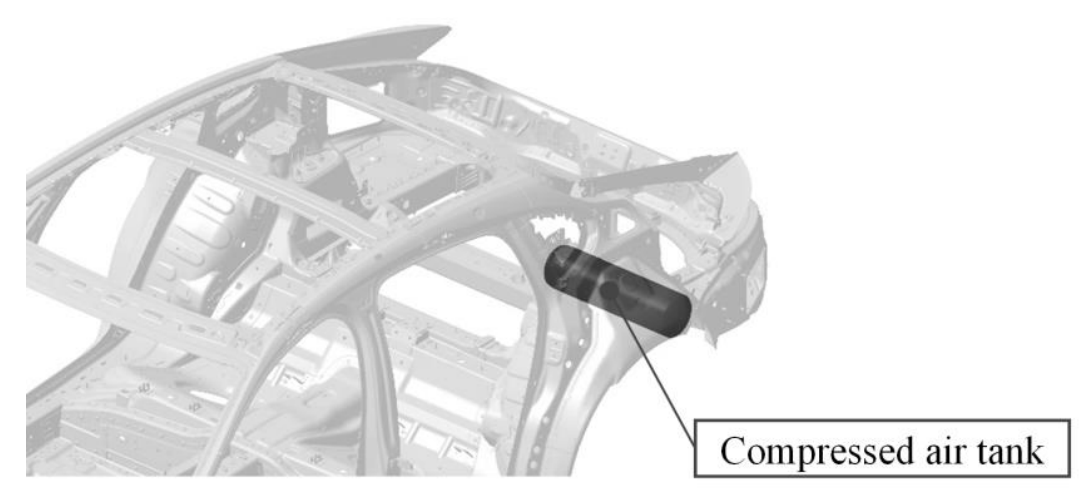

Figure 2. Position of the compressed-air tank in the body-in-white of a Porsche Panamera

Requirements of the compressed-air tank in this case are for instance:

1. Capacity of 8 liters

2. For homogeneous load distribution in the tank wall, the installation space should be as compact as possible and be spherical or cylindrical in shape

3. There is no preferred orientation

4. Possibilities for connections and further routing of the air conductors must be guaranteed

5. Sufficient strength under a pressure of 18 bar

None of these requirements describe the positioning. The compressed-air tank therefore fulfils its storage function independently of its positioning in the vehicle.

Step 2: Since the compressed-air tank can always fulfil its storage function regardless of its position, level 0 is matched to the function carrier.

Step 3: The examination area corresponds to the entire system; in this case, the entire vehicle. Therefore, all components are to be considered, including those which are non-intuitive at first sight.

Step 4: From the requirements determined in step one, requirements R1, R2, R3, and R4 refer to the installation space. Accordingly, various parts constitute potential integration partners. An analysis of the vehicle showed that suitable installation space was located in the area of the cross profiles at the rear of the vehicle, the end of the door sill, the cowl frame, and at the A, B, and C pillars (see Figure 3 A). The analysis was performed as an initial visual inspection of the CAD model of the entire vehicle. Subsequently, further requirements (e.g., safety requirements) were checked and the profiles in the rear of the vehicle (see Figure 3 B) were selected. 

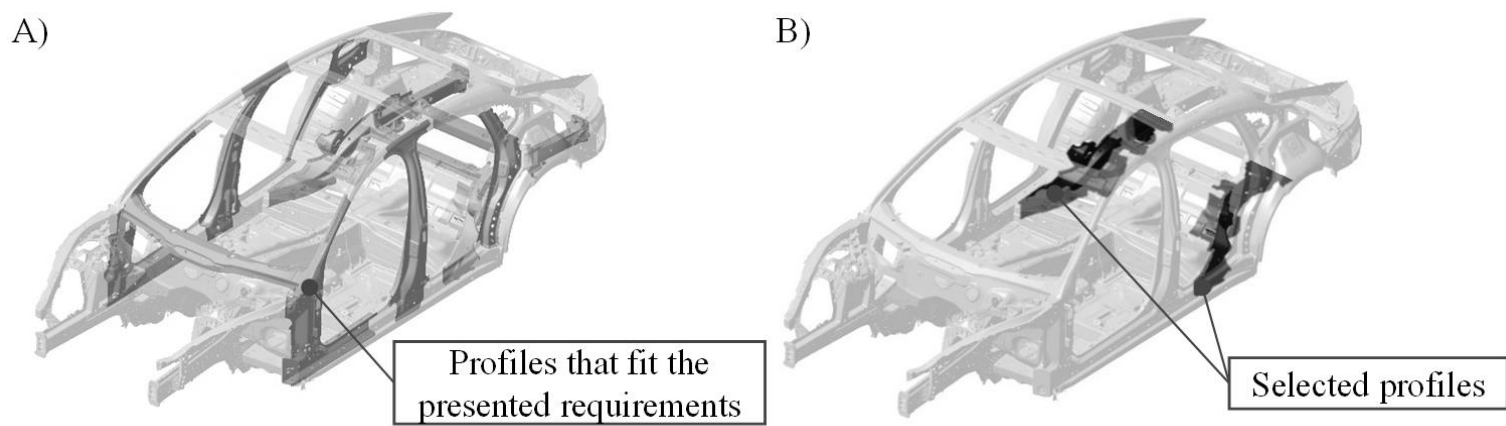

Figure 3. Profiles that fit the presented requirements for installation space of the tank $(A)$ and finally selected profiles $(B)$

\subsection{Example 2: Electrical conductors}

There are numerous electrical conductors in the vehicle. In addition to the on-board electrical system, cables for the powertrain electronics are also installed in cars with electric powertrains. For the second case study, a line for the powertrain was selected (see Figure 4) (Step 1).

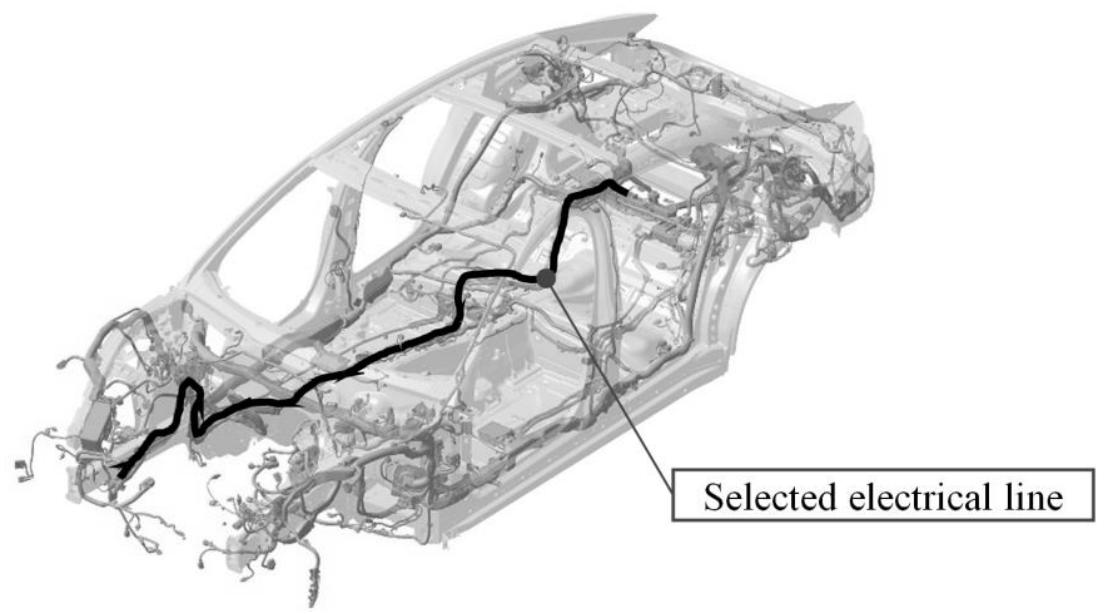

Figure 4. Routing of electrical lines in the body-in-white of a Porsche Panamera

Some requirements for the electrical conductor in this case are:

1. Routing from the HV accumulator to the front electric motor (tied ends)

2. Minimum diameter of the wire (electrical resistance) with regard to economic effects

3. Insulation

4. Shielding

5. As short as possible (low weight)

Of these, only R1 is a position requirement.

Step 2: According to Table 1, the electrical conductor can be assigned to Level 1 of the position binding.

Step 3: The area of interest corresponds to all components adjacent to possible routing courses. A sample of the possibilities is shown in Figure 5 A.

Step 4: Derived requirements for the installation space are as follows:

- The outer diameter of the line including its insulation and shielding must fit into the installation space in accordance with R2 and R3.

The installation space should be long and thin in order to ensure a high degree of space utilization. 

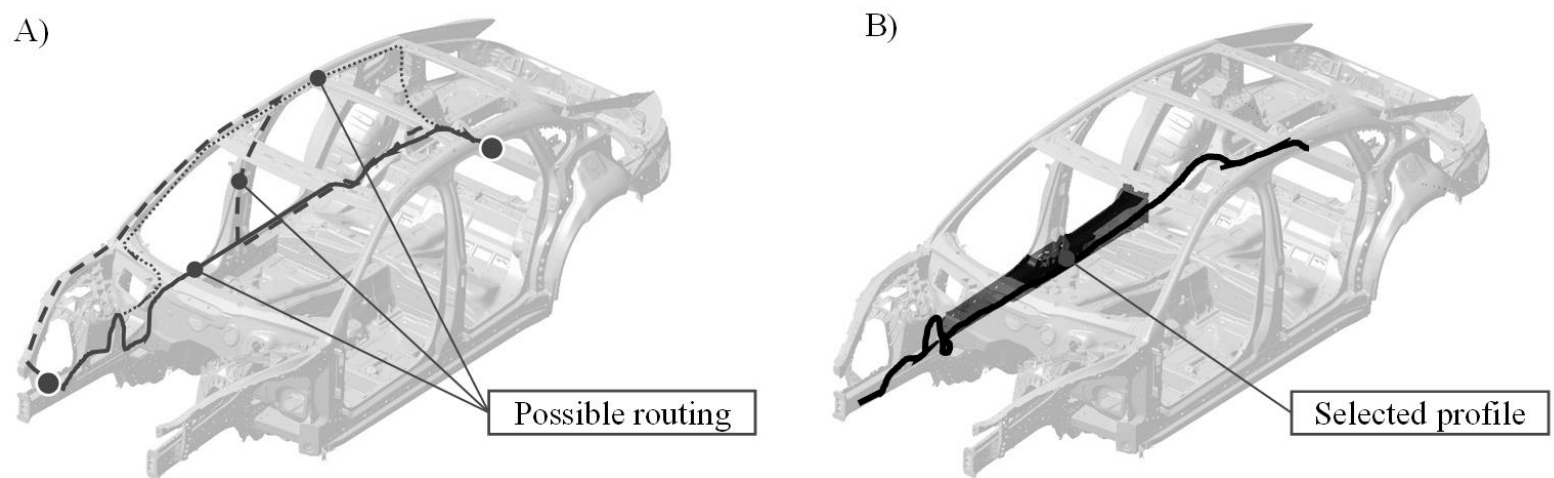

Figure 5. Possible routing for selected electrical line (A) and selected profile (B)

The profile in the door sill (highlighted in Figure 5 B) was selected because of the short distance while meeting the other requirements. Additional requirements such as a low center of gravity are also fulfilled.

\subsection{Example 3: Open drainage (rain gutter) of a building}

The presented procedure can also be applied to architecture or the construction industry, where aesthetic aspects are often the main motivation. The following procedure is described with sketches.

Step 1: Selection: open drainage (see Figure 6 A)

The requirements in this case could be as follows:

1. Draining water from the roof gutter into the drain

2. Minimum gradient to ensure drainage

3. Constant diameter to avoid blockage

4. Protected against corrosion

5. Leak-tight

Of these, only $\mathrm{R} 1$ is a position requirement.

Step 2: The conductor can be fitted to the Level 1 of position binding, in accordance with its requirements.

Step 3: By varying the path, there are several possible structures for an integrative concept. Figure 6 B gives an example (blue structures would fit the requirements).

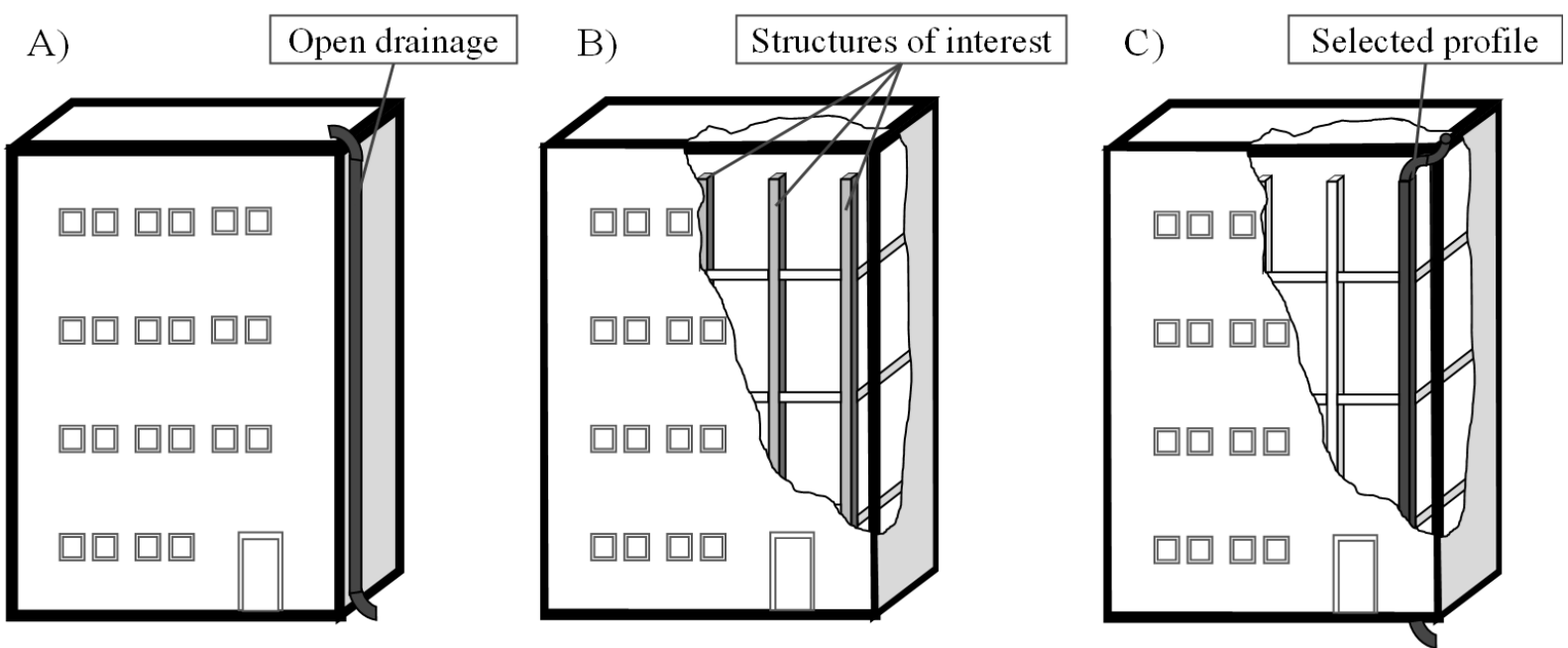

Figure 6. Sketch of a building with open drainage $(A)$, suitable parts of the building structure (B), and the selected profile (C) 
Step 4: Derived requirements for the installation space:

- It should run from the roof to the ground with a minimum gradient according to R1 and R2.

- The cross-section should be constant according to R3.

- The outer diameter of the drainage must fit into the installation space.

- The installation space should be long and thin to ensure a high degree of space utilization.

Figure $6 \mathrm{C}$ shows a possible integrative concept for the open drainage.

\section{EVALUATION}

In addition to verification through case studies, 11 engineers from the fields of product development and lightweight design were interviewed (without the authors). The participants comprise doctoral students from the University of Stuttgart and from TU Braunschweig, as well as engineers from Porsche. $54 \%$ of the participants had already dealt with the topic of functional integration before. After a brief introduction to the topic of functional integration, the main task was to identify suitable integration partners based on the case studies presented above. This was done first without, and afterwards with the assistance of the developed method. Subsequently questions were answered. The results of the survey are presented below:

- How well do you rate your knowledge in the area of functional integration?

- How useful is the method in finding suitable integration partners?

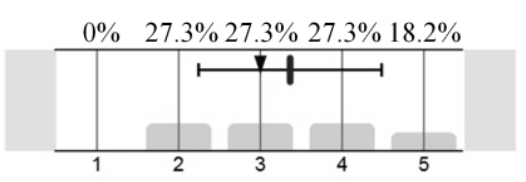

no knowledge high knowledge

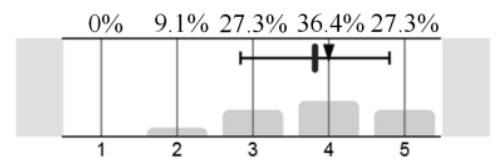

not useful very useful

Furthermore, on the basis of two identified deficits of previous methods, the investigation moved to the issue of whether the new method represents an improvement:

- Previous methods are complex to apply and only numerically solvable to a certain extent (Pimmler and Eppinger, 1994) since the entire system is frequently considered at the same time (Pimmler and Eppinger, 1994; Wulf and Schuller, 2000). Due to the focus on (pre)selected elements at the outset, the application becomes more selective and more practical.

- Methods work with complex forms/tables (Pimmler and Eppinger, 1994; Köckerling and Gausmeier, 2003; Franke et al., 2005; Ziebart, 2012), which are time consuming to create and edit. This makes application in industry more difficult. The developed method dispenses with this and assists in the fast and direct identification of possible integration partners.

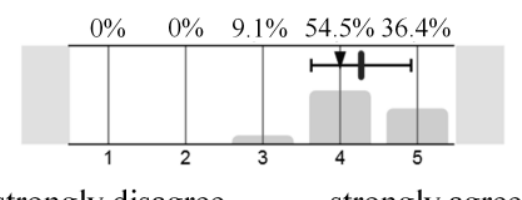

strongly disagree strongly agree

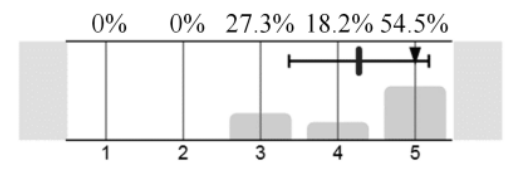

strongly disagree strongly agree

\section{CONCLUSION AND DISCUSSION}

The presented method assists in the selection of suitable integration partners for integrative concepts and avoids the preparation and editing of any additional forms or tables. The method was emerged 
through the development of more than 80 integrative concepts with the help of CAD models. The finding was that identification based on the position specifications and the existing installation space was effective. Position specifications of functions are repeated and can be classified into four identified levels of position binding, which enable a systematic search for installation space and integration partners for integrative concepts. Based on the general view taken in this paper, the method is applicable across disciplines (mechanical engineering, vehicle construction, architecture). The investigations have great potential for application in practice since technical systems are becoming increasingly complex and integral solutions enable the realization of different types of potential. Particularly in the case of vehicles, there is also an ecological potential since weight and installation space and thus resources and fuel consumption can be reduced. The presented case studies show the effectiveness of the method. The first evaluation of the method in practice confirms its benefits compared to existing approaches. However, due to the smaller number of participants (11), it needs to be tested further. In particular, it should be investigated why usefulness tends to score lower than the other criteria and how this compares with existing methods. Based on the results, the support of the method can be further expanded.

\section{REFERENCES}

Aurisicchio, M., Eng, N., Ortiz Nicolas, J., Childs, P., Bracewell, R. (2011), “On the functions of products”, Proceedings of the 18th International Conference on Engineering Design (ICED 11), Lyngby/Copenhagen, Denmark, pp. 443-455.

Bhardwaj, J., Yadav, A., Chauhan, M. S., \& Chauhan, A. S. (2021), "Kano model analysis for enhancing customer satisfaction of an automotive product for Indian market”, Materials Today: Proceedings. Advance online publication. https://doi.org/10.1016/j.matpr.2021.02.093

Delogu, M., Del Pero, F., Pierini, M., (2016), "Lightweight Design Solutions in the Automotive Field: Environmental Modelling Based on Fuel Reduction Value Applied to Diesel Turbocharged Vehicles", Sustainability, 8(11), 1167. https://doi.org/10.3390/su8111167

Ehrlenspiel, K., Hundal, M. S., Kiewert, A., \& Lindemann, U. (2007), “Cost-Efficient Design”. Berlin, Heidelberg: Springer-Verlag Berlin Heidelberg. https://doi.org/10.1007/978-3-540-34648-7

Ehrlenspiel, K. and Meerkamm, H. (2017), "Integrierte Produktentwicklung: Denkabläufe, Methodeneinsatz, Zusammenarbeit", 6th ed., Hanser, München, Wien.

Franke, H.-J., Crull, S., Koschorrek, R. and Krusche, T. (2005), "Faszination Karosseriebau - Innovationen für zukünftige Karosseriekonzepte”, in Faszination Karosserie, GZVB Gesamtzentrum für Verkehr, Braunschweig, pp. 13-31.

Gumpinger, T., Jonas, H. and Krause, D. (2009), "New approach for lightweight design: from differential design to integration of function", Proceedings of ICED 09, 17th International Conference on Engineering Design, Palo Alto, California, USA.

Klaiber, D., Fröhlich, T. and Vietor, T. (2019), "Strategies for function integration in engineering design: from differential design to function adoption", Procedia CIRP, Vol. 84, pp. 599-604. https://doi.org/10.1016/j.procir.2019.04.344.

Köckerling, M. and Gausmeier, J. (2003), "Systematisches Entwickeln der Wirkstruktur mechatronischer Systeme", HNI-Verlagsschriftenreihe No. 122, pp. 217-229.

Laufer, F., Roth, D. and Binz, H. (2019), "Derivation of criteria for identifying lightweight potential - a literature review", Proceedings of the Design Society: International Conference on Engineering Design, Vol. 1 No. 1, pp. 2677-2686. https://doi.org/10.1017/dsi.2019.274

Moritz, J., Seidel, A., Braun, B., Brandao, A., Pambaguian, L., Köhler, B., Leyens, C. (2019), "Functional integration approaches via laser powder bed processing”, Journal of Laser Applications, 31, 22319, https://doi.org/10.2351/1.5096097

Pahl, G., Beitz, W., Blessing, L., Feldhusen, J., Grote, K.-H. and Wallace, K. (Eds.) (2007), "Engineering Design: A Systematic Approach”, 3rd ed., Springer-Verlag London Limited, London. https://doi.org/10.1007/978-1-84628-319-2

Pimmler, T.U. and Eppinger, S.D. (1994), "Integration analysis of product decompositions", Proceedings of the 1994 ASME Design Technical Conferences, Vol. 68, pp. 343-351.

Wagner, C., Ahmels, L., Gramlich, S., Groche, P., Monnerjahn, V., Müller, C., \& Roos, M. (2017), "Finding New Opportunities: Technology Push Approach", Manufacturing integrated design: Sheet metal product and process innovation, pp. 275-299. https://doi.org/10.1007/978-3-319-52377-4_8

Wulf, J. and Schuller, J. (2000), "Entwicklungsmethodik für mechatronische Karosseriesysteme", in Mechatronik - mechanisch/elektrische Antriebstechnik, VDI-Berichte, VDI, Düsseldorf, pp. 181-198.

Ziebart, J.R. (2012), Ein konstruktionsmethodischer Ansatz zur Funktionsintegration, Dissertation, Institut für Konstruktionstechnik, TU Braunschweig, München. 